\title{
Ecological Convergence in the System of Sustainable Development of the Russian Economy
}

\author{
Sergey Zhironkin ${ }^{1}$, Olga Zhironkina ${ }^{2,}$, and Dawid Szurgacz ${ }^{3}$ \\ ${ }^{1}$ Siberian Federal University, 660075 Lida Prushinskaya St. 2, Krasnoyarsk, Russia \\ ${ }^{2}$ Kemerovo State University, 650043, 6 Krasnaya St., Kemerovo, Russia \\ ${ }^{3}$ Center of Hydraulics DOH Ltd, ul. Konstytucji 147, 41-906 Bytom, Poland
}

\begin{abstract}
Currently, studies of the problems of convergence of leading countries in terms of the lean use of natural resources, the reduction of harmful emissions and the transition to using new types of energy carriers are highly relevant, with regard to sustainable development mainstream. At the same time, the majority of authors consider convergent processes from an economic or socio-political point of view. In this regard, the article examines the issues of ecological convergence, as a special structural shift in the economy, leading to radical positive changes in the environmental management system and a decrease in anthropogenic impact on the environment.
\end{abstract}

\section{Introduction}

Lack of attention to the need for pursuing an active and balanced with the economy environmental policy increases the divergent distance of countries that have different understanding of the essence of sustainable economic growth and further weakens the prerequisites for environmental convergence. This is quite consistent with the theory of the "Great Convergence" Ch.I. Jones and L. Pritchett, explaining the fact that developing countries in the 1980-1990s showed higher growth rates than developed ones, but since the 2000s per capita GDP growth has slowed in many developing countries [1].

This is explained, firstly, by the impending structural shift in developed countries, initiated by massive investment in environmental innovations, a jump in the production of green energy and decarbonization, and a massive inflow of highly skilled labor force in the IT industry and nanotechnology. Secondly, the international transfer of environmental innovations occurs in a "club" manner, i.e. between a limited group of countries whose economies are institutionally, technologically, and industrially ready to accept new standards of environmental management. The rest of the countries, primarily developing ones, show growth not due to endogenous (reproductive, market-competitive, innovative and technological), but due to exogenous factors (mainly due to the growth of raw materials production) [2].

\footnotetext{
* Corresponding author: o-zhironkina@mail.ru
} 


\section{Materials and Methods}

We proposed a convergent typology of sustainable development based on the factors, criteria and types. It is based on the factors of structural changes, both in the economy and in the use of natural resources.

The first factor of structural shifts is the mobility of production factors, which means the possibility of their effective redistribution between industries and sectors of the economy (internal mobility) and between countries (international mobility). This applies primarily to labor and capital. The effect of this factor is in the cross-sectoral flow of investments, retraining of the labor force and changing the priorities of vocational education, attracting foreign investment under the influence of significant incentives. Such incentives can be endogenous (high returns on green investments, effective institutions for sustainable development, developed infrastructure for environmental restoration, macroeconomic stability) and exogenous (international specialization of the economy). As a result, the mobility of factors of production is decisive for changes in the sectoral and reproductive structure of environmental management.

The second factor, the diffusion of environmental innovation, characterizes diffusion between industries, its nature and driving forces, and technological convergence. According to E. Rogers, the processes of innovations transfer from science to production, their intersectoral connection, the borrowing of technologies and know-how can be carried out by economic entities voluntarily (focusing on private benefit), collectively (within corporations, associations), and by an imperious decision [3]. While the environmental leadership of countries with developed market economies is ensured by private benefit, in the Russian economy the state uses predominantly directive measures to collectively enforce environmental innovations. However, despite all measures to coerce innovations, Russian state corporations are not leaders in the efficiency of environmental management.

The third factor - "green" innovative entrepreneurship - is a combination of production factors, the effectiveness of which determines the attractiveness of the economy for investing in environmental innovations, organizing start-ups, and commercializing know-how in mass production. Ultimately, the combination of technologies, material resources and labor into a single innovative product is a determining factor in sustainable economic growth - a process that underlies sigma convergence. It means that countries with industrial production, focusing on its environmental modernization, demonstrate lower growth rates of per capita GDP, than countries whose GDP is growing extensively (due to the favorable situation on the world raw material market, i.e. beta-convergent). However, in countries with intensive growth (such as South Korea, Singapore), per capita GDP growth is more stable than in countries that had beta convergence (Russia, with a characteristic outstripping global growth rates in the $2000 \mathrm{~s}$ and a decline in 2010 s years) [3].

The fourth factor - social well-being - is directly related to the involvement of human capital in ensuring a positive structural change through a radical increase in labor productivity in the process of mass creation, commercialization and diffusion of innovations. The effect of this factor lies in the formation and elitization of environmentally oriented social groups, in the growth of the intellectual workers' income in comparison with the extraction of minerals, in the acceleration of scientific and inventive, innovative and entrepreneurial social lifts, in the priority of intellectual rent over raw materials in the tax benefits formation.

The fifth factor - structural policy - is the institutionalization of the state's efforts to stimulate the mobility of factors of production, in particular, the inter-sectoral flow of capital and labor, the implementation of the achievements of scientific and technological progress. In the methodology of extractive and inclusive institutions, the economic policy of the state can be carried out in the interests of the elites. That allows redistributing accordingly public finances, alienating property and income (extractively) or inclusively - in the interests of a 
wide range of the business community, guaranteeing the inviolability of property, taking into account public requests, including innovations [4]. At the same time, sustainable growth under the conditions of the domination of extractive institutions is possible, but it is short and does not lead to a significant increase in the well-being of the population, in contrast to inclusive institutions. We believe that these provisions can be transmitted into environmental policy, which can be formed based on the interests of representatives of the raw material lobby, state corporations and defense industry enterprises (extractively), or take into account the interests of high-tech business, innovative entrepreneurship, stimulate scientific and industrial integration, guarantee intellectual property rights (inclusive). Accordingly, different initial imperatives for the formation of environmental policy institutions will lead to opposite results when initiating a structural shift that brings the economy closer or further away from developed systems.

The sixth factor - the reaction to external shocks and import substitution - is associated with a certain reaction of firms and the state to devaluation surges, the imposing embargoes and international sanctions, and unfavorable changes in world prices. The structural shift that can be caused by externally caused imbalances in supply and demand, the redistribution of production factors and a change in the efficiency of their use in the course of import substitution depends on the nature of the latter. In particular, import substitution may mean the conservation of outdated industries in an attempt to reproduce most of the consumer goods and means of production in the country (i.e., have an autarkic character). In addition, it may be accompanied by an expansion of the place of "green" producers in global production chains (expanded participation in the international division of labor, neoindustrial import substitution), contributing to structural convergence.

\section{Results and Discussion}

The criteria of ecological convergence are signs by which one can distinguish the nature of the action of their factors:

1. Reproduction criteria (the rate of accumulation, autonomous investment, age and depreciation of fixed assets, accelerated depreciation). These criteria make it possible to assess the possibilities of ecological modernization of industry and the prospects for a modernization "breakthrough" - an increase in the share of "green" industries in GDP due to the massive renewal of means of production and a dramatic increase in labor productivity, in the process of changing ecological generations of machinery and technology.

2. Criteria of the economy's perceptibility to environmental innovations (intensity of commercialization of inventions, transfer of innovations). Special role here is played by innovations in new sources of energy [5] and industrial safety [6] - key stones of extracting industries sustainable development.

It is possible to assess the ecological identity of an economy using these criteria. Ultimately, positive changes in the technological structure are multiplied by changes in the structure of value-added production, economic efficiency of firms, and social groups.

3. Diversification criteria (distribution of types and sources of "green" investment, including foreign, sectoral and technological diversification of production, import dependence). These criteria indicate the possibility of environmentally oriented modernization of the economy to the level of the most advanced countries.

4. Market criteria (the share of unprofitable enterprises, the proportion of public and private investments in the innovation sector, the share of small and large businesses in it, the state of the infrastructure for supporting entrepreneurship). The role of these criteria is to determine the development level of market mechanisms in the field of innovative entrepreneurship and its impact on the initiation of a positive structural shift. 
5. Social criteria (quantitative and qualitative characteristics of the labor force in the field of environmental research and development), with the help of which it is possible to assess the potential for increasing the factorial environmental efficiency of labor in the economy as a whole.

6. Institutional criteria (availability and effectiveness of environmental tax incentives, government guarantees and subsidies, public-private partnerships in the environmental sphere) [7-8] indicate the initial prerequisites for a structural shift - the rules and regulations that determine intersectoral capital flows.

These criteria make it possible to assess the degree of convergence of the country's economy and compare it with other technologically advanced countries (which, in principle, can be taken as a stationary state) in the process of greening industrial production.

Based on the above criteria and factors of structural changes in their relationship with ecological convergence, we have identified their types:

1. Ecological convergence, which initiates the conditional convergence of the economy with a characteristic approximation of its structure to the most developed countries, first of all, in terms of the level of nature management and environmental restoration, reproductive, technological and sectoral, social proportions, and environmental parameters. It is precisely ecological convergence, due to its irreversibility, that can create conditions for a long-term sustainable trend.

In turn, the criteria for a convergent structural shift are the following:

- an increase in the accumulation rate up to $30 \%$, autonomous investments up to $50 \%$, technologically related foreign direct investment up to $15 \%$ of gross;

- reduction in the average age of fixed assets to 7 years and physical wear and tear to $40 \%$; - commercialization of innovations up to $85 \%$, reduction of the share of the extractive sector in GDP to $5 \%$, in investments - up to $7 \%$, in exports - up to $20 \%$;

- an increase in the share of the high-tech sector in GDP, exports and investments - up to $10 \%$;

- a reduction in the share of unprofitable enterprises to $20 \%$ and an increase in the share of private investment to $75 \%$ of total investment in innovation;

- an increase in the share of people employed in organizations and divisions of R\&D companies, research institutes and innovative start-ups up to $7 \%$.

At the same time, per capita GDP should approach 20 thousand dollars (which is typical for the countries of Eastern Europe; in the Russian economy in 2014 it was 14.1 thousand, and in $2018-9.9$ thousand dollars), and the general trend of economic growth should be persistently positive (with an acceptable short-term U-recession) [1].

The prerequisites for environmental convergence include an increase in direct investment in the greening of production, a change in the structure of employment in favor of the environmental and educational sectors in one cycle (5 years), an increase in demand for innovation and know-how from industry, the growth of innovative start-ups, the formation of elite highly intellectual social groups, expansion of innovative tax incentives, budget subsidies.

The relationship between the phenomena of technological, structural, ecological convergence and a convergent structural shift is shown schematically in Fig. 1 


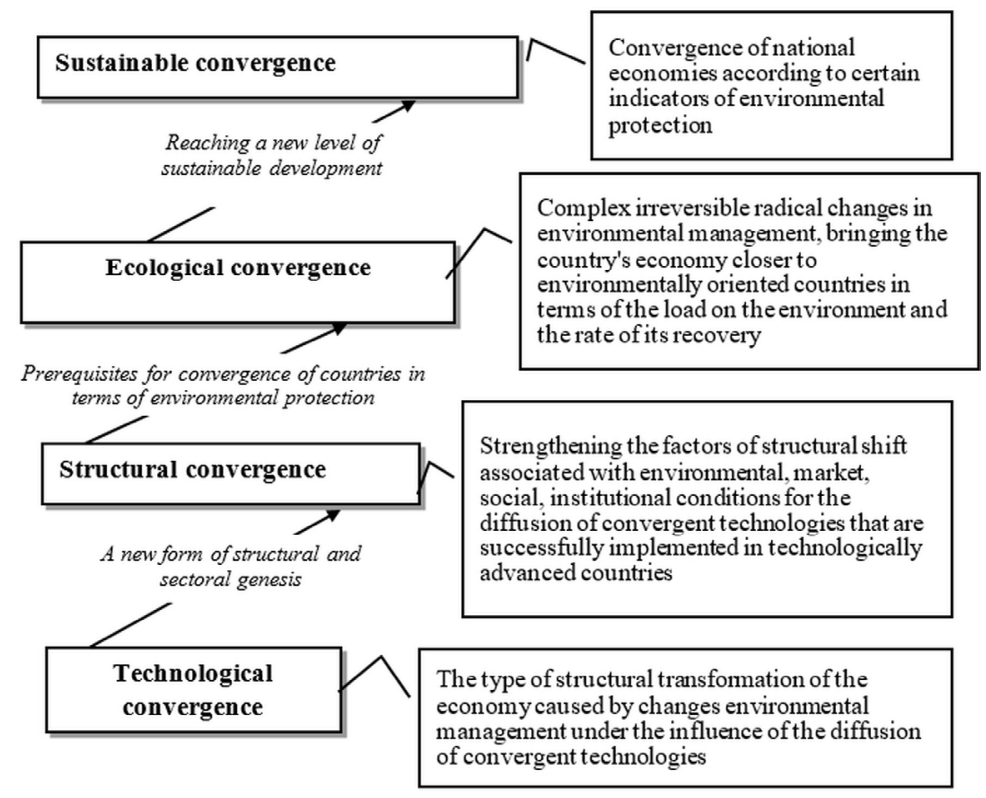

Fig. 1. Scheme of the structural nature of ecological convergence.

As follows from Fig. 1, ecological convergence is the result of factors that form structural convergence, embodied in irreversible complex transformations of the environmental management system, induced by the expansion of convergent technologies [1]. Ultimately, a convergent structural shift is at the core of ecological convergence.

2. Ecological divergence, as the antagonistically opposite of ecological convergence, means the separation of the economy from the advanced countries in terms of ecological, sectoral, innovative technological, social indicators of environmental management. The characteristic of the divergent shift is also the instability of economic growth, the presence of prolonged Land W-recessions (long-term negative rates or near-zero fluctuations in GDP). The reasons for environmental divergence are due to the cumulative negative effect of such factors as a reduction in the outstripping imports of environmental technologies, the collapse of ecologically active social groups, a drop in demand for nature-saving innovations from the private sector, and a structural policy in the interests of resource and financial elites.

Environmental divergence criteria include the following:

- reduction of investments in environmental protection and "green" technologies below $10 \%$ of the total volume;

- cessation of import of environmentally friendly technologies within the framework of foreign direct investment, increase in the average age of fixed assets over 10 years and physical depreciation over $60 \%$;

- commercialization of less than $25 \%$ of innovations;

- growth of the raw materials sector by more than $10 \%$ of GDP and $30 \%$ of exports, and the "green" sector - less than $10 \%$;

- decreasing per capita GDP below \$ 10,000 (the world average in 2017).

It is important to note that ecological divergence is not identical with a negative structural shift, although they have similar features that characterize the primitivization and degradation of the economy structure. A negative structural shift reflects quantitative deterioration in structural proportions, while divergence reflects a decrease in the quality of the structure. This means not only a quantitative "failure" of structural proportions, which in itself has a negative impact on sustainable development, causing recessive and stagnant processes in 
nature management [9]. More importantly, environmental divergence qualitatively removes the country's economy from technologically advanced countries with developed market economies, which radically changes its place in global value chains - as a net exporter of raw materials and a net importer of processed and high-tech products, provokes capital outflow, import dependence, and decline in living standards.

Therefore, it can be argued that ecological divergence is determined by the technological primitivization of the economy (in conjunction with the deterioration of reproductive conditions). For example, deindustrialization takes place both in the Russian economy and in the economies of the United States and Western Europe. However, in Russia it has the character of a technological primitivization of industry, while in Western countries it is an increase in the production of intangible products.

Thus, the ecological divergence is caused, first, by the growing technological lag and the loss of the technological identity of the economy, gaps in the rates of reproduction and labor productivity. Along with this, a decrease in the mobility of factors of production is accompanied by a decrease in the quality of market institutions and the state, which makes the transition to sustainable development difficult, exposes the economy to the destructive impact of manmade disasters.

3. Ecological quasi-convergence is a kind of divergence that satisfies some criteria of ecological convergence - mainly the growth of incomes in the sectors of the green economy, the reduction in the extraction of raw materials and environmental pollution. The fundamental difference between ecological quasi-convergence and true convergence lies in the approaching of the indicators of raw materials extraction and emissions to technologically advanced countries, while maintaining and deepening structural imbalances in the field of investing in environmental protection measures and "green" industries, introducing resourcesaving innovations. At the same time, the institutions of sustainable development, including the most important ones - property rights, measures of structural policy - remain undeveloped [11].

The short duration of ecological quasi-convergence is manifested in the short duration of environmentally oriented economic growth, which turns into frequent and protracted recessions, in an increase in import dependence and an increase in the volume of pollution and the number of manmade disasters. The prerequisites for the transition of ecological quasiconvergence to divergence can be both endogenous (lagging in labor productivity, increasing import dependence and unequal international exchange of added value, the inability to generate new technologies, lack of investment resources), and exogenous (depletion of mineral deposits, crop failures, natural disasters, decreasing of world prices for resources).

\section{Conclusion}

Thus, both ecological convergence and divergence are caused, first of all, by profound changes in technological and reproduction proportions in the economy, and change its place in the system of global chains of production of goods. Innovative transformations associated with the convergent technological stage of scientific and technological progress open up new opportunities for sustainable development and change the nature of the "green" economy, which is becoming dominant.

\section{References}

1. E.A. Taran, Convergent structural shifts in the economy: thesis (SFU, Krasnoyarsk, 2020) 
2. S.K. Demchenko, M.S. Zlotnikov, T.A. Melnikova, O.S. Demchenko, International Journal of Civil Engineering and Technology, 10(2), 1877-1884 (2019)

3. E.V. Shavina, Economics and Innovation Management, 3, 4-13 (2019) DOI: 10.26730/2587-5574-2019-3-4-13

4. S.K. Demchenko, J.J. Suslova, A.S. Yamschikov, I.R. Ruyga, T.A. Melnikova, Journal of Applied Economic Sciences, 12(1), 194-205 (2017)

5. M. Beer, R. Rybár, M. Cehlár, S. Zhironkin, P. Sivák, Energies, 13(10), 2450 (2020)

6. M. Tutak, J. Brodny, D. Szurgacz, L. Sobik, S. Zhironkin, Energies, 13(18), 4891 (2020)

7. V.V. Guzyr', Economics and Innovation Management, 4, 4-19 (2019) DOI: 10.26730/2587-5574-2019-4-4-19

8. M. Cehlar, Economics and Innovation Management, 3, 24-31 (2019) DOI: 10.26730/2587-5574-2019-3-24-31

9. M. Cehlár, J. Janočko, Z. Šimková, T. Pavlik, E3S Web Conf. 15, 01019 (2017)

10. M.A. Klimovich, M.A. Gasanov, Economics and Innovation Management, 2, 8-17 (2019) DOI: 10.26730/2587-5574-2019-2-8-17 